\title{
Influence of disability on maternal care
}

\author{
Thais Pousada García, Paula Madrid Martínez, Javier Pereira Loureiro, Betania Groba \\ González, Encarnación Díaz Martínez
}

Faculty of Health Science, University of A Coruña, A Coruña, Spain

\begin{abstract}
The purpose of the study was to examine how women with physical disabilities perceive the influence of their disability on maternal care during the first 3 years of their child's life, to describe the main difficulties that they must deal with everyday when taking care of their children and to determine which resources, either material or human, and/or strategies that are used for this purpose. The study used a qualitative approach. Conversational techniques (semi-structured interviews) were used to assess the effect of mothers' physical disabilities during the first 3 years of their child's life. The study involved participants from the Northwest region of Spain called Galicia. Different points of view regarding the influence of disability on motherhood (especially the influence of disability on maternal care), as well as the influence of a disability on children are identified. The main difficulties these mothers have had to struggle with, as well as the strategies used to overcome them, are also identified. The results obtained in this study show that it is clear that society needs to become aware of these mothers' testimonies in order to eradicate the existing negative stereotypes regarding disability. In addition, the creation of a service that promotes maternal care is proposed, thus empowering women with disabilities in their maternal role.
\end{abstract}

Keywords

Physical disability; Motherhood; Maternal care; Occupational therapy; Spain

\section{Introduction}

Motherhood is one of the most important roles for women [1]. When a mother gives birth to a child, she becomes involved in a new life project. This new role will change their lifestyle, and it will surely modify her habits and routines, and for the rest of the family as well. It constitutes a permanent role, so maternity is for a woman's entire life. There are different functions that a mother can perform, and they are going to depend on her cultural background and social and physical environment.

Although it is one of the many roles a woman can take on during her lifetime, even currently, women are not equally incorporated into diverse living environments. For example, there are gender inequalities for women with children who try to get or to maintain a job.

\section{Women and Disability: The Double Discrimination}

Moreover, any factor that can influence the development of this maternal role ${ }^{1}$ will have a great importance on their self-esteem and self-determination, as can having a disability. This concept, disability, is an umbrella term, defined by the International Classification of Functioning (ICF), as functioning in multiple life areas. These include domains such as simply seeing, walking, taking a bath, working, going to school, accessing social services and many others. So, a disability is seen as a result of an interaction between a person (with a health condition) and that person's contextual factors (environmental factors and personal factors). Disability covers a spectrum of various levels of functioning at the physical level (impairment), personal level (limitation in activity) and societal level (restriction in participation). With this in mind, it can be established that impairment does not determine a difficulty to 
perform activities or to develop a role. Indeed, impairment is referred to as a problem in body function or its structure that may or may not affect performance. Thus, disability is a complex phenomenon, reflecting an interaction between features of a person's body and features of the society in which he or she lives [2].

If attention is focused on the discrimination that women suffer, the most accentuated and unnoticed type is that suffered by women with disabilities. For a long time, their social handicap has been ignored, which is known as double discrimination. In addition to the limitations inherent to their disability, there exist physical and social barriers, such as lack of urban accessibility or negative stereotypes, among others. Therefore, their sense of competence, understood as "the ability to deal effectively with the demands of their individual roles" [3], may be modified.

As such, double discrimination refers to the fact of being a woman and having a disability. According to the National Institute of Statistics (NIS) in 2008 in Spain, there were 2,300,200 women with some type of disability or limitation regarding daily activities [4]. This means that $10.2 \%$ of women in Spain (those that have a disability) [4] are victims of double discrimination, which, among other circumstances, affects motherhood, modifying their ability to fully take on this role. The consequences of this double discrimination are related to increased exclusion and situations of violence; therefore, these women are at an increased vulnerability.

The Universal Declaration of Human Rights says that "Men and women, of full age, have the right to marry and to found a family, with any limitation or restriction [...], and they are entitled to equal rights" [5]. To ensure this equality in situations in which vulnerabilities exist, the Convention on the Rights of Persons with Disabilities was created. This Convention refers to the present topic in several articles.

At present in Spain, there is a Comprehensive Plan of Action for Women with Disabilities that analyzes the main causes of discrimination and associated factors. This document proposes tools and resources to improve this situation. Their objectives are directed towards promoting independence, personal autonomy and self-determination of women with disabilities. With respect to maternity, actions are related to multidisciplinary care aimed at resolving the problems associated with the demands of motherhood, or facilitating access to assisted reproductive systems [6].

Despite the adoption of the cited texts, there are still significant obstacles for these mothers when fulfilling their role. Catalogs of assistive products do not include devices that make their parenting experience easier [7]. In addition, social and health services enhance the personal care of women with disabilities; however, they do not provide any support for their role as mothers. Priority is given to medical aspects regarding disability instead of motherhood, but the interaction between them should be taken into account. Lack of accessibility is also a form of discrimination because it hinders or even prevents the mother's full participation in her child's education or leisure activities.

\section{Empowerment and Facilitation of Performance in Mother's Care}

With the development of their maternity's role, all mothers, with and without disability, assume the same responsibilities and daily stressors that are related to the upbringing and care of their children. As such, satisfaction is mixed with their fear of incompetence. In the case of women with disabilities, this feeling could be different, and their sense of self-competence could be altered.

Therefore, an analysis of needs and demands related to the performance of their motherhood's activities seems required to find and obtain adequate solutions to overcome those obstacles. In this sense, occupational therapists have great experience and knowledge in the analysis of activities that can be adjusted to the demands of a person within his or her environment. These adjustments allow a person to participate in their occupation or activity correctly.

Occupational Therapy (OT) seeks to empower people by emphasizing the importance of making the right choices, that is, those that contribute the most to their health, well-being and quality of life. To overcome the obstacles that these women may encounter in their daily life, especially when taking care of their children, the demands of these activities should be analyzed. Solutions that make everyday life easier for these mothers should then be explored and found. OT may be defined as "the art and science of enabling engagement in everyday living, through occupation; of enabling people to perform the occupations that foster health and well-being [...]" [8]. This includes facilitating parenting and, more specifically, providing the required care and supervision to support the developmental needs of a child [3].

The end goal of this profession is to help people with special needs to be able to fully take part in significant occupations. This project has been approached from the perspective of occupational therapy, because motherhood is a significant role for women (and all of them have the right to get involved) and 
that role implicates specific activities with important consequences for these women, including women with disabilities.

\section{State of Art}

Nevertheless, little research is currently being conducted regarding the effects of disabilities and persistent illnesses on motherhood [8,9]. Historically, medical and professional literature has not referred to any issues regarding the sexuality and reproductive health of women with disabilities. These topics are still absent in occupational therapy's literature, but not in other disciplines such as nursing or psychology [10-12]. The role of mothers with disabilities continues to be invisible in the wider society [7].

Given the existing gap, undertaking research from this perspective is necessary. This will enable the determination of how physical disability affects mothers when taking care of their children. Maternal care and, hence, the functions of a mother, as well as the child's needs during development, vary as the child becomes older. Therefore, maternal care has been evaluated at a specific stage, particularly the first 3 years of a child's life.

The main objective of this study is to determine how mothers with physical disabilities perceive the influence of their disability on maternal care during the first 3 years of their child's life. Secondary goals include (1) describing the main difficulties that they must deal with every day when taking care of their children, and (2) determining which resources, material or human, and/or strategies are used for this purpose.

\section{Methods}

In this study, a qualitative approach was used in order to explore this phenomenon in its natural environment. This way, an interpretation can be constructed from the meanings people express about their experiences. This study is part of a phenomenological paradigm that understands social phenomena from the actor's perspective, with a focus on what people experience regarding the phenomenon and the way they interpret these experiences [13].

\section{Scope and Sample Selection}

Theoretical sampling was used as a tool of qualitative research to deliberately select participants. With this method, the real goal was not to representatively capture all possible variations, but to gain a deeper understanding of analyzed cases and facilitate the development of an analytic frame and the concepts used. The scope of this research was limited to Galicia (a region of Spain with 2,695,880 inhabitants). Details regarding inclusion and exclusion criteria are provided in Table 1.

Table 1. Selection criteria to recruit participants

\begin{tabular}{|c|c|}
\hline Inclusion criteria & Exclusion criteria \\
\hline Existence of movement and mobility impairment & $\begin{array}{l}\text { Once the information was read, not signing an informed consent } \\
\text { form }\end{array}$ \\
\hline $\begin{array}{l}\text { Disability status has been officially recognized (under the } \\
\text { Spanish law) }\end{array}$ & $\begin{array}{l}\text { Not having enough cognitive ability required to give the } \\
\text { interview }\end{array}$ \\
\hline Be a mother & $\begin{array}{l}\text { Physical disability was acquired after the first } 3 \text { years of the } \\
\text { child's life }\end{array}$ \\
\hline $\begin{array}{l}\text { Presence of physical disability during the first } 3 \text { years of the } \\
\text { child's life }\end{array}$ & Not living in Galicia \\
\hline
\end{tabular}




\section{Participant Characteristics}

The sample included eight women who were mothers with a physical disability between 36 and 60 years old (mean age of 45.5 years). Table 2 contains information regarding the diagnosis and the degree of disability of each of the participants. The mean age at giving birth was 30.92 years old.

Table 2. Characteristics of participants

\begin{tabular}{lll}
\hline Participants & Diagnosis & Degree of disability (\%) \\
\hline & & 85.0 \\
M1 & Facioscapulohumeral muscular dystrophy (FSHD) & 34.5 \\
M2 & Slipped discs, cervical disc protrusions and denervations in the upper limb & 49.0 \\
M3 & Charcot Marie-Tooth & - \\
M4 & Renal transplantation, cancer & 41.0 \\
M5 & Rheumatoid arthritis & - \\
M6 & Crest syndrome & 70.0 \\
M7 & Right hemiplegia and aphasia & 53.0 \\
M8 & Left brachial palsy &
\end{tabular}

All but two of these mothers made the conscious decision to be mothers with disabilities. Regarding their marital status, all of the participants were married except for one of them who became divorced shortly after giving birth. In regard to their current employment status, four of them were working when this study was performed, while the other four, after being assessed by the Disability Assessment Team (Equipos de Valoración de la Incapacidades, EVI), were declared unfit to work (permanent total or severe disability).

\section{Procedures and Data Analysis}

First, the purposes of this work were presented to different non-profit social organizations (NGO) for them to disseminate among their users. Thus, those users that were interested in participating could join the research group. Those women who decided to take part in the study signed an informed consent form and received a copy of it. Real names and places have been modified in order to respect their anonymity. The occupational therapy code of ethics was taken into account. Information was collected by means of semi-structured interviews with the participants (see Table 3). 
Aspects regarding the interaction between motherhood and disability

How was raising your children? Do you believe that you had difficulties?

Regarding child care tasks (bathing, dressing, feeding a child...), which task required more effort?

What about playing and leisure activities?

Which positive aspects do you think your child has acquired as a result of interacting with disability?

Strategies and resources (material and human)

Were you working before giving birth? How did you organize yourself? Was it necessary to give more priority to family care over your professional career?

How well did you do in your everyday life? Did you need some type of support (caregiver, childcare provider, etc.)?

Regarding couple organization, how did you deal with housework and taking care of your child?

Did your family or friends help you? In that case, who?

Which material modifications or adaptations did you need?

Mothers' point of view regarding the influence of disability on motherhood

Was there anything that worried you regarding motherhood or child care?

How do you think disability has influenced motherhood for you?

Data analysis was planned as circular process, beginning at the time of data collection, with subsequent analysis open to modification. The analysis was based on the interpretation of the participants' experiences, looking for the verbatim with more meaning along the speech from participants. Data from each of the interviews were compared and analyzed in order to determine the study's findings.

\section{Results}

Eight emerging categories were obtained from the data collected from the interviews. These data describe in detail the participants' perceptions regarding the influence of their disability on motherhood as well as how these two factors interacted in their daily life. The original quotations were recorded in Spanish and then translated into English to publish them. Below are the characteristics of each emerging category. Those participants quoted are identified using abbreviations composed of the letter $\mathrm{M}$ and their number as a participant, as shown in Table 1.

\section{Main Difficulties and Positive Aspects Regarding the Interaction Between Motherhood and Disability}

The main reported difficulties were related to neuro-musculoskeletal functions or personal mobility. This was due to the characteristics inherent to the participants' disabilities, with motor skills usually the most compromised.

Mobility and lack of sensitivity, lack of strength, both for holding and bathing them, among others... (M3)

Therefore, support was necessary when they were carrying out tasks that require these functions. This was especially relevant when, apart from having limited mobility, there was some type of strength or sensitivity impairment.

\section{Strategies and Resources Used by Mothers with Disabilities}

During the performance of their daily occupations, mothers with disabilities developed a series of strategies depending on their capabilities and limitations. This enabled them to carry out daily activities in a more autonomous and easier way. However, there were resources to support these mothers. These were material resources, such as assistive devices or environmental modification, or human resources, which were categorized either as formal or informal support. 
It was precisely because of the difficulties I thought I would find that I tried to use means of support. For example, using a baby bath tub, so that the baby is resting in it and there is no need to hold him. (M8)

Although some strategies were initially developed in order to overcome the mother's difficulty, these could be useful for anyone, making the task more efficient or comfortable.

They were really heavy for me (talking about her children), so I used to hold them against my chest. In the end, my husband did the same thing. It was more comfortable for us. (M2)

When a strategy was developed, the most important thing was not how the process itself was carried out, that is, the way in which the different activities for which there existed some type of limitation were carried out. On the contrary, the fact that doing it differently facilitated the performance of these tasks with greater autonomy. It should be considered that they took advantage of their capabilities and thus reduced the difficulty of the tasks.

The thing is not that you can't, it's that you have to do it, and when you do it, you must find a way in which you don't see you can't... not that you're doing it the wrong way because you can't do it in any other way, but that these strategies allow your child to be the way he is supposed to, but somehow else. (M1)

Depending on each mother's situation, the support received was different. On one hand, some mothers found formal support, which will be described in more detail subsequently, and, on the other hand, others obtained informal support, which normally involved family (i.e., partner or extended family) or friends.

I didn't hire anyone, but I did have my mother's help. [...] My parents have always been an unconditional support for me, for my child. (M6)

Children also represented an important support for the participants. As mentioned previously, as these children grow up, they can provide greater support for their mother.

Well, right now, given his age, as I already told you, he is the biggest support that I have at home (talking about her son). (M6)

\section{Interaction of Motherhood, Disability and Employment}

In this type of interaction, the need for support becomes even more obvious. However, it is worth highlighting that the mothers of this study, in general, felt that their disabilities did not influence this need's existence. That is, combining work and motherhood was complicated without any external help.

Well, I believe that this is a need that anyone who wants to work and have children at the same time will have, regardless of having some kind of disability. (M8)

\section{Mothers' Perceptions Regarding the Influence of Their Disability on Their Children}

This section will address not only the positive but also the negative experiences of children living with a mother with a disability as perceived by the mothers. The mothers emphasized that their children became more autonomous, reliable and mature, and did so earlier, as compared to those who do not interact with a disability at home.

They are more autonomous; they learned to fend for themselves earlier. (M4)

In addition, disability also had an influence on children's participation and collaboration with housework. These children usually assumed family responsibilities, helping with household chores from an early age.

It is worth highlighting that the education these children received at home was something to take into account regarding this particular matter. However, it seems that there was a difference in why they did 
these chores; while in these homes, these chores were carried out to support the mother, in others it seems that they were carried out as a result of obeying parental authority.

At another home maybe they do it to obey but... here I think they may understand better what participating means. (M1)

Mothers also believed that their children developed attitudes and values such as tolerance and respect as a result of being in contact with disability from an early age.

I think tolerating difference is strength. (M8)

One mother emphasized how she believes her disability has affected her children, positively and negatively. She felt that everyday life could lead to overloading the family.

There's sometimes a need to set free... the emotional life of each of them. (M1)

\section{Mothers' Perceptions Regarding What Their Children Think About Their Disability}

This section depicts how mothers described their perception of what their children think about them and their disability and their role as a mother compared to other mothers without disabilities.

When the children were little, some mothers were unable to explain to what extent their children were aware of their disability. Another point of view is that children did realize their mothers performed activities in ways that were different than those that do not have any type of disability. However, these differences were assumed to be normal.

He realizes I can't, that I can't clap like other people or that I don't hold things with both hands like other people do. (M8)

It is also believed that children were aware of their mother's limitations and, hence, they tried to support them by helping them when necessary.

Then I think they realize that... you're not like the other mothers and they care and are attentive. (M1)

There seems to be a correspondence between these three perspectives and different age ranges. Depending on the child's age, their perceptions of both their mothers and themselves would change. As children grew, they became more aware of their mothers' disabilities and what these disabilities imply.

\section{Concerns Regarding Motherhood and Child Care}

Broadly speaking, the major concern expressed by mothers with disabilities who participated in this study was the inability to properly take care of their children. That is, they doubted their skill to take care of their children.

Simply... not being able to do things... it distressed me. (M6)

Another concern was the possibility of transmitting the disability. One mother was worried, at first, that her children would inherit her disease, although the disease was not hereditary. Nonetheless, this concern disappeared when they were born.

I was worried that they may have the same disease that I had, although it wasn't necessarily hereditary. (M4)

The lack of experience in child care seemed to be a key factor and, what is more, being a new mother, reflected greater fears and insecurities. 
It was the only experience I had with a child [...] so I was scared to hold him, hmm, the typical movements, well, what's usual, right? (M8)

In contrast, not being a new mother, that is, having some experience in taking care of a child, was a positive aspect; mothers felt more secure and the concerns were less.

I wasn't a new mother, so I wasn’t scared anymore. (M2)

In general, these concerns tended to disappear once the child was born and the mother started taking care of their child.

Maybe it was more the fact, hmm..., of knowing whether I was prepared or not, if I had the necessary capabilities... when the moment came it was much easier. (M8)

In fact, many of these concerns seemed to be very similar to those expressed by mothers without disabilities, especially in the case of new mothers. That is, their thoughts seemed to be more related to motherhood itself than to performing the activities of motherhood while having a disability.

Another participant reported not having any concern regarding motherhood.

I was never scared, neither for one nor for the other one, of anything. (M1)

\section{Mothers' Perceptions Regarding Other People's Concerns in Relation to Disability and Motherhood}

Sometimes, insecurities regarding the capabilities of the mothers to take care of their children were external to them. On one hand, there were people who were close to the mothers (such as the partner, family or friends) and, on the other hand, there were those within the health sector.

First of all, the opinions of those people closest to them had a more direct effect. Sometimes, as shown previously, these people were great supports. However, conversely, these people's attitude towards the mother caused greater difficulties.

I think the father was the most scared person in relation to this disease. When he found himself in the situation of a person already having a problem and [...] a child born at twenty-nine weeks [...]. I think he felt he wouldn't be able to cope with all of this. Thus, I think that, to let him look good, he was very scared, but then he... he didn't change his mind. (M6)

In addition, society sometimes became a barrier to their performance at motherhood, causing sometimes, limitations in addition to those inherent to the disability.

(Talking about her daughters) When they saw the people worrying, they felt scared. Well, because sometimes people made inappropriate comments to girls that age. (M4)

The global perspective of the participants was that there seemed to be a wide diversity of opinions among health professionals regarding the interaction between a mother's disability and child care. This seemed to depend on the type and degree of disability as well as the context (i.e., the location where it took place).

I think that, at a medical level, at least in Spain huh... they prioritize or see mostly the disability and not the possibilities of motherhood, that for sure [...] (talking about Brussels) They make you see things, and they will talk to you clearly, but they will ask you: do you feel qualified? They will never tell you that you're not qualified. (M1) 
Given the heterogeneous diagnosis regarding the participants, there are a variety of opinions included below.

One perspective, shared by several participants, was to highlight only the positive aspects of their disability. These mothers believed that their disability had positive effects on their children, enabling them to develop attitudes and values of vital importance for them.

I think that, overall, it can be something positive. Not only because he is becoming more sensitive towards me, but also towards any human being. (M6)

Another opinion was that the disability did not have any influence on their role of motherhood. It did not seem that their responsibilities as a mother were altered at any level due to the disability so that the children were not affected by it.

Knowing the limitations due to disability and how it specifically affected their children, there was a maternal need to compensate for these limitations by other means.

You try to compensate with other things... I don't know... well, you go more often to the park with them or... you take them with other friends so that they have fun. (M5)

One mother referred to an alteration of "maternal autonomy" in relation to a specific aspect such as carrying out activities outside the home alone with her children.

Because I had that vivid picture in my mind, other mothers my age who would go shopping with their daughters of around fourteen. I couldn't do that, not alone with her. (M1)

It is worth highlighting that disabilities that affected motor skills produced a decrease in the amount of physical activities that were carried out as a family. That is, it affected performing these activities together, but this does not imply that the children did not perform physical activities. However, there was no location where it was possible to carry out activities that required physical effort as a family so that every member could participate as part of a collective.

Well, I think that, for example, disability has contributed to the family being less physically active. (M1)

Another point of view regarding the influence of disability on motherhood was the elaboration of organizational strategies and planning activities. This allowed mothers to avoid complications even before they appeared and facilitated their resolution.

I plan each activity very much in order to solve or try to cover the needs that I may have before having to deal with them. (M8)

\section{Discussion}

The main goal of this work was to analyze how women perceived the influence of their disability on taking care of their children during the first 3 years of their children's lives. Another objective was to explore the resources and strategies used by these mothers as well as to identify the main difficulties they found in their daily life while taking care of their children. Therefore, a series of categories (related to each other) that explained this phenomenon of the influence of disability on maternal care have been obtained.

Currently, in Spain, health aspects regarding disabilities are usually prioritized over maternity. Mothers with a disability believe that a pregnant woman with a disability must be seen, first, as a pregnant woman. Disability is not necessarily the major concern of a woman who has decided to have children [14].

The development of sexuality and reproductive capability is directly linked to a person's dignity and to the free development of his or her personality. They are protected through several fundamental rights, especially those that ensure physical and moral integrity as well as personal and family privacy (Sexual and reproductive health and abortion law, 2010) [6]. As shown in this work, it is necessary that, like any other woman, mothers with disabilities have the necessary resources to enjoy a successful maternity. 
Different health systems are implemented in different countries, but it is clear that studies about the impact of resources used to ensure minimum assistance in mothers with disabilities are required. Moreover, the design of specific family planning programs (taking into account special needs of each disability), the creation of points of information and mutual assistance among women with disabilities, and monitoring the implementation of legislation are also necessary to get correct assistance and orientation to mothers with disabilities, and to empower them $[6,11]$.

Implications for the practice of health care professionals (especially for occupational therapists) and for changes in clinical approaches require that specific programs to attend to the needs and demands of women with all types of disabilities need to be created. This program should be planned by taking into account the assessment of women and their capacities, their social and health resources, and their environment. With this in mind, the assistance will be able to focus directly on their needs due to deficiencies and consequences of the disabilities in each mother, applying the client-centered practice.

After performing a bibliographic search and analyzing the results of this work, it is obvious that there is a need to perform more exhaustive research focused on studying maternal care in relation to children of mothers with disabilities at other age ranges (e.g., childhood, school age and adolescence) in order to detect the different needs that mothers may have during those phases. Different age groups have different characteristic challenges and rewards [14]. Moreover, to reduce the possible biases in asking about difficulties, interviews should be extended to women without disabilities. These women would constitute a control group.

For future studies, the informants' profiles must be redefined. It has become evident that the type of disability affects the mothers' perspectives and their difficulties in everyday life when taking care of their children. It has also been demonstrated that there is a need to study the perspective of other relevant people, such as partners and children, as well as that of health professionals and social service workers.

Finally, exploring the different demands required by child-care activities will allow the most appropriate support resources depending on the needs of each user to be created, designed and applied.

All of these suggestions for research and clinical practice will contribute to improve the health and social assistance to women with disabilities, and hence, their self-determination and quality of life.

\section{Conclusions}

Research regarding the interaction between maternity and disability is scarce. Therefore, if women's realities are not studied, public administrations and society in general will continue to have high levels of ignorance.

Thus, it is evident that there is a need to inform different social agents about the current situation, needs and requirements of mothers with physical disabilities. Hence, certain negative stereotypes that remain regarding how a disability can alter the performance of the maternal role could be eliminated.

Moreover, there is a need to assess and determine whether the current legislation regarding disability, gender and maternity is effective. Similarly, the level of practical application of the current regulations must be determined. Taking into account the lack of resources in Spain, in order to support disabled mothers in their role as mothers, the creation of a service, which promotes this support and takes into account interventions offered by Occupational Therapy as an empowering discipline, is proposed with the support of other professionals, such as social workers, psychologists or nurses. This service could involve environmental modifications, adapted techniques and/or skills training regarding this role among other things. This way, the mother's sense of competence and personal identity will be strengthened. The final goal is for mothers to achieve full participation in their children's education and upbringing.

\section{Compliance with Ethical Standards}

\section{Conflict of interest}

The authors declare that the research was conducted in the absence of any commercial or financial relationships that could be construed as a potential conflict of interest.

\section{Ethical aspects}

All procedures performed in studies involving human participants were in accordance with the ethical standards of the institutional and/or national research committee and with the 1964 Helsinki declaration and its later amendments or comparable ethical standards. Informed consent was obtained from all individual participants included in the study. 


\section{References}

1. Esdaile, S., Olson, J.: Mothering Occupations Challenge, Agency and Participation. F.A. Davis Company, Philadelphia (2004)

2. World Health Organization: International Classification of Functioning, Disability and Health-ICF, 1st edn. WHO, Geneva (2001)

3. American Occupational Therapy Association: Occupational therapy practice framework: domain and process. Am. J. Occup. Ther. 56(6), 609-639 (2002)

4. National Statistics Institute: Survey on disability, personal autonomy and dependency situation. 2 (2008). http://www.ine.es/jaxi/menu.do?type=pcaxis \&path=\%2Ft15\%2Fp418\&file=inebase $\& \mathrm{~L}=1$. Accessed $10 \mathrm{Sept}$ 2013

5. United Nations: Universal declaration of human rights (2009). http://www.un.org/en/documents/udhr/index.shtml. Accessed 2 Sept 2013

6. Peláez Narváez, A., Martínez Ríos, B., Leonhardt Gallego, M.: Maternidad y Discapacidad. CERMI, Madrid (2009)

7. Reid, D., Angus, J., McKeever, P., Miller, K.L.: Home is where their wheels are: experiences of women wheelchair users. Am. J. Occup. Ther. 57(2), 186-195 (2003)

8. Crepeau, E., Cohn, E., Schell, B.: Willard \& Spackman's Occupational Therapy, 11th edn. Lippincott Williams \& Wilkins, Baltimore (2009)

9. Poole, J.L., Willer, K., Mendelson, C.: Occupation of motherhood: challenges for mothers with scleroderma. Am. J. Occup. Ther. 63(2), 214-219 (2009)

10. Toms Barker, L., Maralani, V.: Challenges and Strategies of Disabled Parents: Findings from a National Survey of Parents with Disabilities. Berkeley Planning Associates, Oakland (1997)

11. Prilleltensky, O.: A ramp to motherhood: the experiences of mothers with physical disabilities. Sex. Disabil. 21, 21-47 (2003)

12. Olkin, R., Abrams, K.: Parents with Disabilities and their Adolescent Children Final Report. Through the Looking Glass, Berkley (2003)

13. Polit, D.F., Beck, C.T.: Nursing Research, Principles and Methods, 7th edn. Lippincott Williams \& Wilkins, Philadelphia (2004)

14. Rogers, J.: Guía para la Mujer con Discapacidad: Del embarazo al parto. Fundació Institut Guttmann, Barcelona (2006) 